\title{
Food availability and consumption at national, household and individual levels: implications for food-based dietary guidelines development
}

\author{
Lluís Serra-Majem* \\ Department of Clinical Sciences, University of Las Palmas de Gran Canaria, P.O. Box 500, 35080 Las Palmas de \\ Gran Canaria, Spain, \& Community Nutrition Research Group. Barcelona Science Park, University of Barcelona, \\ Spain
}

\begin{abstract}
The three levels of dietary data national, household and individual, are analysed and compared, and their use and misuse in FBDG development and monitoring are discussed. Food Balance Sheets (FBS) estimate the national availability of foods, and are an appropriate tool to evaluate food policies; they tend to overestimate food consumption, particularly for those foods with higher waste. Household Budget Surveys (HBS) estimate the household availability of foods, and are useful to evaluate dietary family interventions. Individual Dietary Surveys (IDS) evaluate individual food and nutrient intake and provide a unique estimation of nutritional status and are the best tool for planning FBDG; however, they are expensive and may be biased towards underreporting.

The understanding of the relationship between the different levels of food information is very important when formulating, evaluating and monitoring a nutrition policy in a country or region.
\end{abstract}

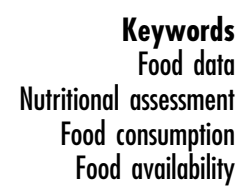

Keywords Food data ood consumption Food availability

\section{Introduction}

Within a food policy context, nutrition planning requires an understanding of food consumption patterns. Two types of dietary data are collected regularly in most developed countries: agricultural supply and utilisation data in the form of food balance sheets (FBS) as prepared by the Food and Agriculture Organisation of the United Nations (FAO), the Organisation for Economic Cooperation and Development (OECD), Eurostat, or national administrations, and household budget survey (HBS) data ${ }^{1,2}$. In addition, most countries sporadically conduct individual dietary surveys (IDS) based on nationally representative population samples. Special surveys, conducted at regular intervals, could be used to describe the usual food consumption and nutrient intake patterns of the population ${ }^{1,3}$. However, the high cost of these surveys has prohibited their periodic establishment in many countries on a national level. Instead, they have been conducted using different methodologies in specific population groups or in local samples. HBS tend to overestimate consumption of certain foods compared to IDS, and to underestimate food consumption data in comparison to FBS by at least 20\% ${ }^{4,5,6}$

Regarding nutrition policy, individual data on food consumption and energy and nutrient intakes provides the most appropriate information since they may be segregated by age and gender, thereby enabling the identification of high-risk population groups. However, household and national data may also be very useful in a nutrition policy context since they provide a rough but useful estimation of food and nutrient availability.

The objective of this study is to analyse the usefulness of the different food data and their appropriateness in planning and monitoring nutrition intervention in communities.

\section{Methods}

Different authors have compared food data between countries using different dietary methods, of which some are analysed here.

FBS are constructed by the FAO from national accounts of the supply and use of foods. Data are calculated from the food produced and imported for countries as a whole, subtracting food exported, fed to animals, or otherwise not available to humans, and dividing by the population to obtain average values per person/year. In wealthy countries, food availability estimated by FBS are clearly overestimated, but in other developing countries this figure may be underestimated. Methodology of FBS has been analysed in detail elsewhere ${ }^{1}$. HBS are organised to 
analyse family expenditure in order to calculate the consumer price index, and to analyse areas of social and economic interest. Normally they are implemented by National Institutes of Statistics or Economics and cover a high number of households. Generally, the food consumed outside the home tends to be underestimated and this seems to be the main weakness of these data. The methodology of HBS in Spain has been described in detail, as well as in other countries 5 and in particular, in the comparative study DAFNE (Food data networking) ${ }^{7}$.

IDS are conducted by national or regional Ministries of Health and include random population samples. There are several methods to collect food data at the individual level, including recalls and records, and frequency questionnaires. One of the major weaknesses of IDS is the increasing tendency towards underreporting, which seems more relevant in certain population group (youth, obese people,...) (see underreporting issues in this volume). Most national IDS in Europe and America include 1 to 3 24-hour recalls or 1 to 7 dietary records 8 .

FBS and HBS results can, in principle, be easily compared between countries, as the methodologies used are similar ${ }^{2}$, IDS include several methods of food intake collection (food frequency questionnaires, 24hour recall, record methods, etc.) which make comparisons more difficult ${ }^{9}$. A clear advantage of IDS over the other methods is its capacity to segregate data into different age and gender groups, but particularly to describe the distribution of nutrient intakes in populations (see variability issues in this volume). This allows the analysis of food and nutrient intake distributions to be combined, which is the basis of the development of FBDG $^{8}$

\section{Results and discussion}

Recently, a WHO-CINDI working group has completed a comparative analysis of nutrition data on a national, household and individual level from Canada, Finland, Poland and Spain ${ }^{10}$. Direct comparisons of dietary data between studies were made using FBS, HBS and IDS and comparisons were also made within countries. FBS overestimated food consumption and nutrient intake compared to IDS; results between HBS and IDS were quite similar, except for fish, pulses and vegetables, which were underestimated by HBS, and sugar and honey, which were overestimated. Percentages of energy from fat, carbohydrates and proteins were higher when estimated from FBS, HBS and IDS respectively. Results suggest that estimations from these three sources of dietary data are difficult to compare since they are measuring different levels of dietary information. Authors concluded that the understanding of these relationships may be important in formulating and evaluating a nutrition policy ${ }^{10}$. Figure 1 shows a theoretical scenario of the measurement of fruit availability and consumption in Spain from the WHO-CINDI study using the three levels of dietary information ${ }^{10}$. The intersection between the different areas may explain the amount of fruit consumed within and outside of the home. It also distinguishes between consumption and availability. In Spain, fruit availability was $384 \mathrm{~g} /$ person/day according to FAO FBS data ${ }^{11}$, and $300 \mathrm{~g} /$ person/day according to the National Institute of Statistics HBS data. IDS in Catalonia showed an amount of $277 \mathrm{~g} /$ person/day, which represents $72 \%$ of the total available (FBS). The greater part of the $277 \mathrm{~g} /$ person/day of fruits may be consumed at home, another part outside the home, and the difference between the amount consumed at home and the amount available at home (HBS) may be due to waste and, to a lesser extent, underreporting.

Figures 2 and 3 show average edible fat available at national and household levels, respectively. A major problem arises when comparing food groups, since definitions and items do not completely match. For instance, FBS include vegetables fats as a group, and
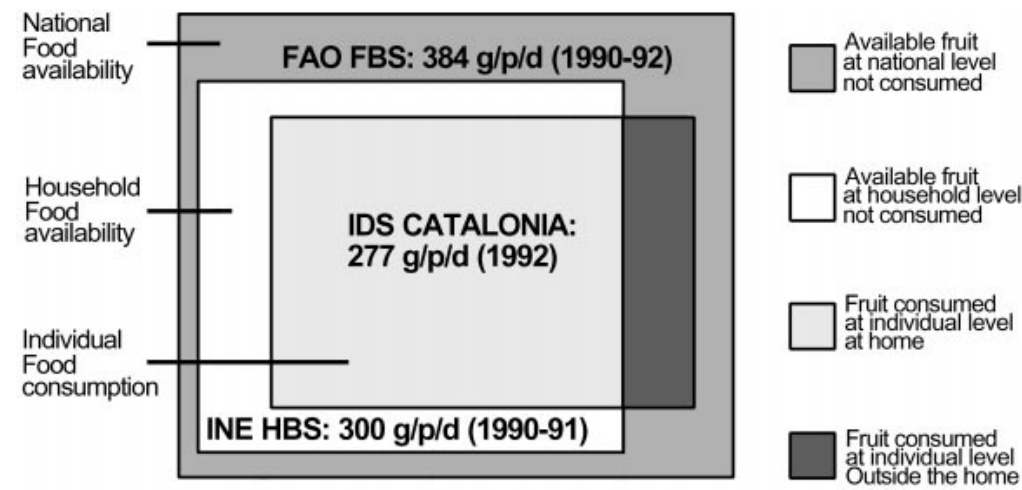

Fig. 1 Fruit availability and consumption in Spain from different sources (1990-92) 


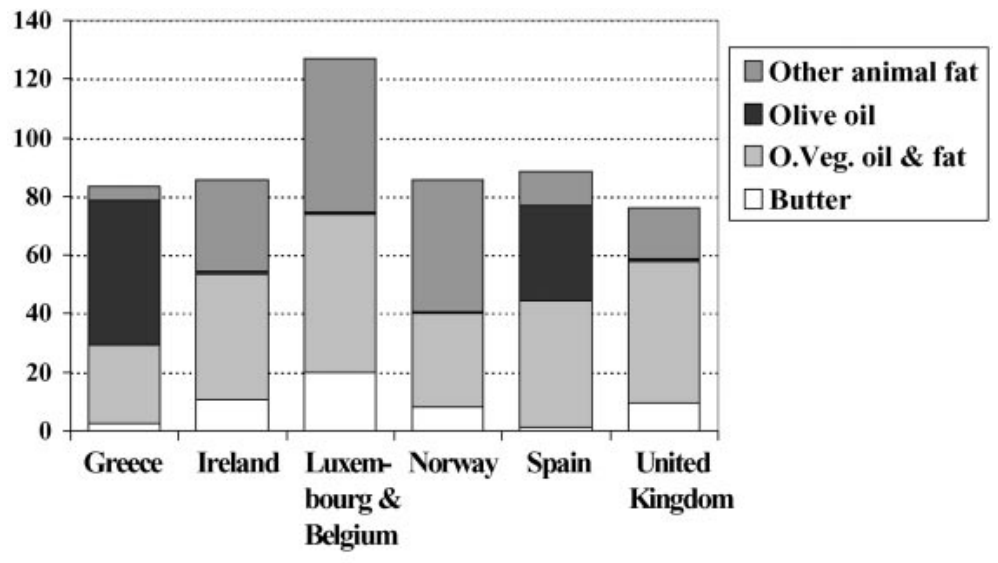

Source: Modified from FAO, 1998

Fig. 2 Average edible fat availability in selected countries according to HBS g/person/day, 1992

distinguishes between vegetable oils (liquids) and vegetable fats (solids). In general, results from HBS and FBS are similar for Greece and Spain, but edible fat estimates by FBS are more than twice the estimates from HBS for other countries. In Ireland, butter availability at the household level is more than twice the butter availability at the national level. However, such limitations and criticism should not be emphasised since the different methods have their own advantages, disadvantages and utilities, and oils and sugars are probably the most difficult items to be estimated by any food consumption assessment method.

Knowing food and nutrient availability is a very important step in developing dietary guidelines, since average individual consumption levels will only be reached if they are available nationally and at a household basis. If available levels of national food consumption are higher than desirable individual levels, nutrition education may have a major role in nutrition policy. Otherwise, if apparent levels are lower than recommendations, promotion of supply or trade may be a priority in policy development. Also, the level of food information required from a nutrition intervention perspective will depend on the scope of the intervention. If the aim is to promote dietary changes at the household level, by education or price interventions, HBS may be the best dietary tool for monitoring changes. If the objective is to promote national food supply changes by legislation, agricultural incentives or international trade, FBS would be the most appropriate tool. However, if interventions are targeted at changing the nutritional status of individuals through education, fortification or supplementation, IDS together with anthropometric and biochemical indicators constitute the most appropriate tools ${ }^{12}$.

The three levels of dietary data provide unique information about the availability and reported intake of food in populations, but their comparisons are difficult to interpret since they represent different stages of the food chain. The understanding of their relationships may be important when formulating, evaluating and monitoring a nutrition policy in a country or region.

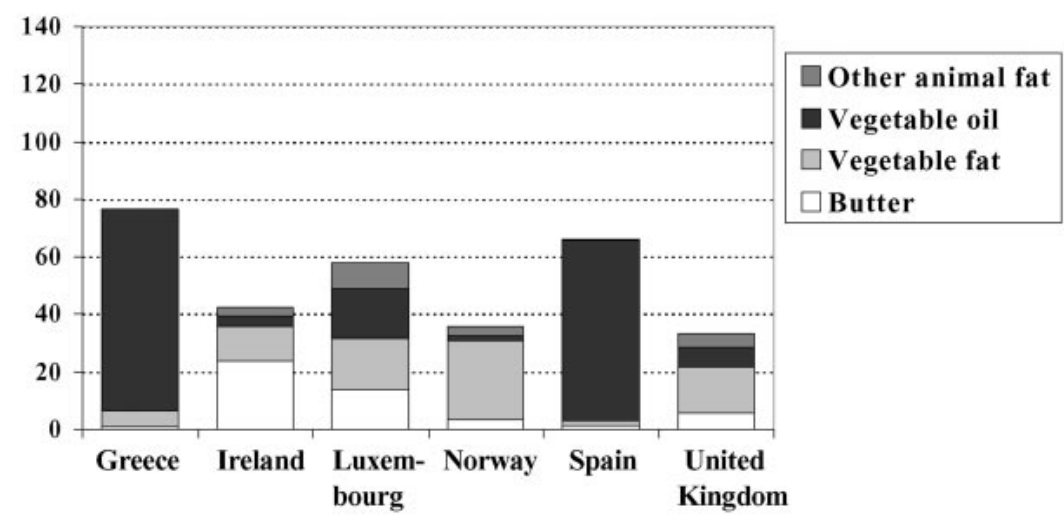

Source: Modified from Trichopoulou \& Lagiou, 1998

Fig. 3 Average edible fat availability in selected countries according to FBS. g/person/day, 1990-92 


\section{References}

1 Becker W, Helsing E, eds. Food and health data. Their use in nutrition policy-making. pp. 1-171. Copenhagen: WHO Regional publication, European Series No. 391991.

2 In: Trichopoulou A, ed. Methodology and public health aspects of dietary surveillance in Europe: The use of Household Budget Surveys. Eur. J. Clin. Nutr. 1992; 46(suppl 5): S1-153.

3 Ferro-Luzzi A, Leclercq C. Nutritional surveillance: an outline. In: Van der Heij DG, Löwik MRH, Ockhuizen Th, eds. Food and Nutrition Policy in Europe. Wageningen: Pudoc Scientific Publishers, 1993: 113-8.

4 Sekula W. Nutrition information systems in Europe. In: Van der Heij DG, Löwik MRH, Ockhuizen Th, eds. Food and Nutrition Policy in Europe. Wageningen: Pudoc Scientific Publishers, 1993: 101-12.

5 Serra-Majem L., Ribas L., Lloveras G., Salleras L. Changing patterns of fat consumption in Spain. Eur. J. Clin. Nutr. 1993; 47: $\mathrm{S} 13-20$.

6 Trichopoulou A, Kanellou A, Lagiou P, Zintzaras E and the DAFNEI I group Integration of nutritional data on household budget surveys in European countries. Proceedings of the Nutrition Society 1996; 55: 699-704.

7 Trichopoulou A, Lagiou P, eds. Methodology for the exploitation of HBS food data and results on food availability in six European countries. Luxembourg: Office for Official Publications of the European Communities, 1998 EUR 18357 EN .

8 EIFS. Food-based Dietary Guidelines- A Staged Approach. Br. J. Nutr. 1999; 81(suppl 2): S29-153.

9 Morabia A, Beer-Borst S, Hercberg S. for the EURALIM Study Group. Locally based surveys, unite! The EURALIM example. Am. J. Public Health 1998; 88: 1153-5.

10 Serra-Majem L, MacLean D, Brule D, Ribas L, Sekula W, Prattala R, Garcia-Closas R, Yngve A, Lalonde M, Petrasovits A. Comparative analysis of nutrition data from national household and individual level: results from a WHO-CINDI collaborative project in four countries. (submitted).

11 FAO. FAOSTAT-PC, Food Balance Sheets 1997. Roma: FAO, 1998.

12 Serra-Majem L. Promoción de una dieta saludable. In: Alvarez-Dardet C, Colomer C, eds. Promoción de la salud y cambio social. Barcelona: Masson, 2000: 78-87. 